\title{
Ossification of Cervical Posterior Longitudinal Ligament: Clinico- Radiological Correlation and Surgical Outcome.
}

\author{
Thokchom Gojendra Singh ${ }^{1}$, ArunkumarSingh Yumnam ${ }^{2}$, \\ K.Rajchandra ${ }^{3}$,Laithangbam PKS ${ }^{4}$, S. Sarat ${ }^{5}$, N. Ratan ${ }^{6}$ \\ Address for correspondence : Dr. Th. Gojendra Singh, Department of Surgery,Regional Institute of Medical \\ Sciences, Imphal ,Manipur, India. Pin :795004.
}

\begin{abstract}
:
Background: The precise contribution of static and dynamic factors to the disease progression of the cervical OPLL ( Ossification of posterior longitudinal ligament) remains controversial. So an attempt has been made to correlate the clinical features with preoperative radiological findings and postoperative outcome.

Methods: After Institutional ethical clearance, written informed consent were taken from 26 patients (31 to 70 years of age) to enroll in this prospective longitudinal study over 3 years period. OPLL was proven radiologically and the degree of preoperative myelopathy was assessed by modified Japanese Orthopaedic Association( mJOA) score. Decompressive laminectomy was performed in all the patients and Hirabayashi's recovery rate was assessed at 3 and 6 months postoperatively.

Results: It was found that poor surgical outcome was correlated with age $>60$ years, duration of myelopathy $>2$ years, preoperative bladder dysfunction ( $p<0.001)$, MRI cord signal changes $(p=0.041)$ and lower cross sectional area of the cervical spinal cord $(p=0.035)$.

Conclusion: Preoperative poor functional status of the patient as well as radiological findings of lower cross sectional area of cervical spinal cord and signal changes in MRI are predictive of poor outcome.
\end{abstract}

Keywords: Laminectomy, myelopathy, neurological, ossification, radiological.

\section{Introduction}

Ossification of the posterior longitudinal ligament (OPLL) was first described by Aston C. Key ${ }^{1}$ of Guys Hospitaln, London in 1838. It then remained unnoticed for a long time until Tsukimoto ${ }^{2}$ in 1960 reported an autopsy case presenting the syndrome of compression of the spinal canal. Ossification of the posterior longitudinal ligament has been recognized as a common clinical entity that causes compressive myelopathy of the cervical spine. Gradually OPLL became established as a disease entity that is distinguishable from ankylosingspinal hyperostosis, ankylosing spondylitis and diffuse idiopathic skeletal hyperostosis.

Now a days OPLL which is most commonly found in the cervical region is a well known cause of cervical myelopathy and / or radiculopathy ${ }^{3}$. OPLL has been found to be strongly associated with regions demarcated as fluoretic belts across the world including those in the Indian subcontinent. Surgical management of cervical OPLL has been characteristically marred by unpredictable outcome. The precise contributionof the static and dynamic forces to the disease progression remains controversial. No long lasting improvement has been obtained by any of the non-operative methods. Conservative treatment has a limited role in the management of cervical OPLL. Surgical treatment should be so delayed that irreversible cord damage occurs.The aims and objectives of the present study are 1) to correlate the radiological findings with clinical features in patients with cervical OPLL and 2) to evaluate the outcome of surgical management.

\section{Methods}

Following ethical committee approval, this prospective longitudinal study was carried out at the department of Neurosurgery, NarayanaHrudayalaya Institute of Medical Sciences, Bangalore, India. Written informed consent was obtained from the patients. A total of 26 patients could be recruited during the three years study period. Patiens with proven OPLL ( on CT and or MRI) having cervical radiculopathy, myelopathy or both were included in the study. Patients having the same neurological findings but due to degenerative diseases, previous surgery, fluorosis of the spine, trauma or neoplasm were excluded from the study. Preoperative clinical evaluation was done using modified Japanese Orthopaedic Association Score (mJOA) ${ }^{5}$.

Modified Japanese Orthopaedic Association Score (mJOA):

I. Motor dysfunction of upper limb Score

- inability to move hands ----- 0

- inability to eat with spoon but able to move hands -----1 
- $\quad$ inability to button shirt but able to eat with spoon-----2

- able to button shirt with great difficulty

3

- $\quad$ able to button shirt with slight difficulty

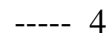

- no dysfunction

\section{Moetor Dysfunction Of Lower Limb}

Score

- complete loss of motor and sensory function

- $\quad$ sensory preservation without ability to move leg

- able to move legs but unable to walk

- able to walk on flat floor with aid

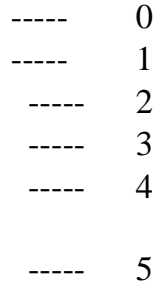

able to walk up/down stairs with hand rail

- moderate to significant lack of stability but able to walk up/down stair without hand rail

- mild lack of stability but able to walk unaided with smooth reciprocation

----- 6

- no dysfunction

III. Sensation Score

- complete loss of sensation

- $\quad$ severe sensory loss or pain

- mild sensory loss

- no sensory loss

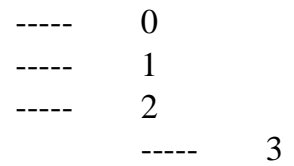

\section{Sphincter dysfunction Score}

- $\quad$ inability to micturate voluntarily

- marked difficulty in micturation

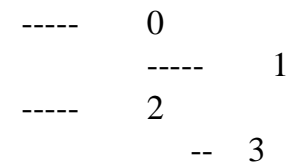

- mild to moderate difficulty in micturation

- Normal micturation

Pre-operatively the stability (maintaining the alignment ) is assessed by dynamic cervical spine $\mathrm{x}$-ray in lateral view. The decision whether the patient should undergo cervical laminectomy alone or with posterior fusion is based on assessment of cervical lordosis or kyphosis. ${ }^{5,6}$. In cervical lordosis the posterior border of all cervical vertebrae lie anterior to more than $2 \mathrm{~mm}$ away from the imaginary line drawn from the dorso-caudal border of $\mathrm{C}_{2}$ to $\mathrm{C}_{7}$.

Decompressive cervical laminectomy usually includes a segment above and below the radiological abnormal segments. Laminectomy is initiated using a high speed air drill to shave down the lamina in the lateral gutters. Once the ventral bony cortex or ligamentumflavum is exposed, micro kerrison punches and micro curettes are used to complete the laminectomies from inferior to superior.

Immediate post-operative status was evaluated clinically in terms of motor, sensory and sphineter functions. Postoperative complications and their management were documented. Detailed clinical evaluations were done at discharge and follow up at 3 and 6 months postoperatively.

Recovery rate was calculated in percentage by the method described by Hirabayashi ${ }^{7}$ at discharge and during follow up.

Recovery rate $=$

$\frac{\text { Post op mJOA Score - pre op mJOA Score }}{17-\text { Pre op mJOA Score }}$ X100

Radiological evaluation when performed post-operatively and at follow-up were done to include certain parameters like changes in canal diameter, kyphosis, alignment of the vertebral bodies etc. stability of the spine was assessed using dynamic $\mathrm{X}$-rays.

Statistical analysis was performed using SPSS15 and strata 8.Q. Descriptive statistics and ANOVA were used where appropriate. A p value of $<0.05$ was considered significant. 


\section{Results}

Demographic profile is shown in Table I.Male : Female ratio is 11.2 ( $84.6 \%: 15.4 \%)$. Highest incidence $(30.8 \%)$ is found in the $4^{\text {th }}$ decade (41-51 years of age). However most of the patients who remained clinically static or worsened postoperatively were $\leq 60$ years of age. Although the Indian sub-continent is included in the fluorotic zone, myelopathy due to fluorosis was excluded from the study.

Table-I: Demographic profile values are expressed as numbers with their percentage in the brackets.

No.of patients : 26

Sex (male:female): $22: 4(84.6 \%: 15.4 \%)$

Incidence with age range:

$\begin{array}{ll}31-40 \text { years } & 15.4 \% \\ 41-50 \text { years } & 30.8 \% \\ 51-60 \text { years } & 26.9 \% \\ 61-70 \text { years } & 26.9 \%\end{array}$

Geographical distribution:

$\begin{array}{llll}\text { Karnataka } & - & 21 & (80.7 \%) \\ \text { Tamil Nadu } & - & 3 & (11.5 \%) \\ \text { Andhra Pradesh } & - & 2 & (7.6 \%)\end{array}$

Most patients (42.3\%) had duration of myelopathy less than 1 year. However 2 patients each in the poor outcome groups (clinically static and clinically worsened) had duration of myelopathy more than 2 years.

\section{Table- II:}

Clinical profile of the patients.

- Duration of myelopathy

$$
\begin{array}{lc}
\text { lopathy } & \text { No. of patients }(\%) \\
<1 \text { year } & 11(42.3 \%) \\
1-2 \text { years } & 4(15.4 \%) \\
3-4 \text { years } & 9(34.6 \%) \\
<\text { 4 years } & 2(7.7 \%)
\end{array}
$$

- Distribution of signs and symptoms

Both upper and lower limb weakness

Sensory symptoms

Gait disturbances

Neck pain

Sphincter dysfunction

- Co-morbid conditions

Hypertension

Coronary artery disease

Both hypertension and diabetes

Table -III

OPLL Characteristics

Number of patients (percentage)

Type . continuous $17(65.4 \%)$

- Mixed 9 (34.6\%)

- Focal $\}^{\text {Nil }}$

\section{OPLL}

Thickness

Level
$3(11.5 \%)$

$1(3.8 \%)$

$1(3.8 \%)$

$90 \%$ confidence Interval

$$
\begin{aligned}
& 49.3-78.6 \\
& 21.4-50.7
\end{aligned}
$$

$$
\begin{array}{lll}
\text { upto } 2 \mathrm{~mm} & 3(11.5 \%) & 4.71-25.60 \\
2-3 \mathrm{~mm} & 10(38.5 \%) & 24.57-54.52 \\
3-4 \mathrm{~mm} & 12(46.2 \%) & 31.21-61.83 \\
>4 \mathrm{~mm} & 1(3.8) & 0.8-15.53 \\
\mathrm{C}_{3}-\mathrm{C}_{5} & 9(34.6 \%) & \\
\mathrm{C}_{3}-\mathrm{C}_{6} & 12(46.2 \%) &
\end{array}
$$




$$
\mathrm{C}_{4}-\mathrm{C}_{6} \quad 5(19.2 \%)
$$

\section{Cross-sectional area of cord at maximum compression}

$\begin{array}{ccccc}\text { Level }(\text { square } \mathrm{mm})<41 & 1 & (3.8 \%) & \\ & 41-50 & 8 & (30.8 \%) \\ & 51-60 & 12 & (46.2 \%) \\ 61-70 & 3 & (11.5 \%) \\ & >71 & 2 & (7.7 \%) \\ \text { MRI cord signal changes } & \mathrm{T}_{1} \text { Hypo } 1 \text { (3.8\%) } & & \\ & & \mathrm{T}_{2} \text { Hyper } & 10 & (38.5 \%) \\ & \text { No change } & 15 & (57.7 \%)\end{array}$

The OPLL type in this study are continuous (65.4\%) or mixed (34.6\%). Maximum number (46.2\%) of patients had cross sectional ( at the level of maximum compression) area of $51-60$ square mm though 2 patients in the poor outcome group had cross-sectional areas of 40.8 and 42 sq. mm.

Table -IVgives an idea of the operative outcome. Nine out of 26 patients $(34.6 \%)$ underwent decompressive laminectomy at $\mathrm{C}_{3-6}$ level followed by lesser number of patients at other overlapping levels. Nineteen patients $(73.1 \%)$ improved at 3 and 6 months follow up. Of the patients in the poor outcome group, 3 patients $(11.5 \%)$ clinically worsened and 4 patients $(15.4 \%)$ remained clinically static.

Table - IV

Operative Outcome of OPLL

\begin{tabular}{|c|c|c|c|}
\hline \multirow{7}{*}{$\begin{array}{l}\text { Parameters } \\
\text { Level of decompressive Laminectomy }\end{array}$} & \multicolumn{2}{|c|}{ No. of patients $\%$} & \multirow{2}{*}{$\begin{array}{c}90 \% \text { confidence Interval } \\
7.10-30.2\end{array}$} \\
\hline & $\mathrm{C}_{2-5}$ & $4(15.4 \%)$ & \\
\hline & $\mathrm{C}_{2-6}$ & $4(15.4 \%)$ & \\
\hline & $\mathrm{C}_{2-7}$ & $4(15.4 \%)$ & $7.10-30.2$ \\
\hline & $\mathrm{C}_{3-5}$ & $1(3.8 \%)$ & $0.8-15.5$ \\
\hline & $\mathrm{C}_{3-6}$ & $9(34.6 \%)$ & $21.4-50.4$ \\
\hline & $\mathrm{C}_{3-7}$ & $5(19.2 \%)$ & $6.7-34.6 \%$ \\
\hline
\end{tabular}

Post Operative complications :

- Chest infection

- Wound discharge

- Lower limb motor Weakness mJOA score 1

- Urinary retention

- Upper limb motor Weakness mJOA score 0

- Persistent neck pain $3(11.5 \%)$

Length of stay in hospital (days) :

$$
\begin{aligned}
& -\quad \leq 5 \text { days } \\
& -\quad 610 \text { days } \\
& \text { - } \quad 6-1-\text { days } 18(69.2 \%)
\end{aligned}
$$

Overall outcome :

$$
\begin{array}{llr}
\text { - } & \text { Improvement } 19(73.1 \%) & 57.1-84.7 \\
\text { - } & \text { Status quo 4 }(15.4 \%) & 7.1-30.2 \\
\text { - } & \text { Worsened } \quad 3(11.5 \%) & 4.7-25.6
\end{array}
$$

Table 5 highlights the poor prognostic factors. Statistical significance could not be demonstrated for some parameters whenwe take the average value. But considering the small number of patients who had poor outcome - clinically static $(n=4)$ and clinically worsened $(n=3)$ and the actual number of patients with the particular parameter, we can get some insight about the correlation of the outcome. Three patients in the clinically static group and 2 patients in the clinically worsened group actually had age $\geq 60$ years. Similarly preoperative mJOA score $<11$ had a tendency towards poor outcome. Preoperative bladder dysfunction $(\mathrm{P}<0.001)$, cross sectional area of the cervical spinal cord at the level of maximum compression $(\mathrm{p}=0.035)$ and MRI cervical cord signal changes $(\mathrm{p}=0.041)$ were clearly predictive of poor outcome. 
Table - V Poor prognostic factors, values are expressed in mean \pm SD (standard deviation).P $<0.05$ is significant

\begin{tabular}{|c|c|c|c|c|}
\hline Parameter & $\begin{array}{l}\text { Clinically improved } \\
(\mathrm{n}=19)\end{array}$ & $\begin{array}{l}\text { Clinically static } \\
(\mathrm{n}=4)\end{array}$ & $\begin{array}{l}\text { Clinically worsened } \\
(\mathrm{n}=3)\end{array}$ & $P$ - value \\
\hline Age(years) & $51.11 \pm 10.43$ & $61.25 \pm 4.78$ & $58.00 \pm 9.17$ & 0.140 \\
\hline Duration of symptoms (years) & $2.34 \pm 1.52$ & $1.75 \pm 2.16$ & $1.63 \pm 2.06$ & 0.690 \\
\hline Postoperative mJOA & $14.42 \pm 1.02$ & $11.00 \pm 1.16$ & $6.67 \pm 1.16$ & $<0.001$ \\
\hline $\begin{array}{lll}- & \text { Bladder dysfunction number of } \\
\text { patients }(\%)\end{array}$ & $1(5.3 \%)$ & $3(75 \%)$ & $3(100 \%)$ & $<0.001$ \\
\hline - $\quad$ MRI Cord signal changes & $5(26.3 \%)$ & $3(75 \%)$ & $3(100 \%)$ & 0.041 \\
\hline - $\quad$ Cord diameter sagittal $(\mathrm{mm})$ & $14 \pm 2.0$ & $11 \pm 1.21$ & $9 \pm 1.0$ & 0.034 \\
\hline - $\quad$ Length of stay in hospital (days) & $7.53 \pm 1.98$ & $7.00 \pm 1.83$ & $10.67 \pm 1.53$ & 0.036 \\
\hline
\end{tabular}

\section{Discussion}

Ossification of the posterior longitudinal ligament is a common cause of cervical myelopathy. Inspite of these, there are definite uncertainties as regards its etiology and treatment options. For those patients above 65 years of age with rapidly progressive myelopathy and several co-morbid conditions are managed conservatively because of the increased risk of morbidity and mortality ${ }^{8}$. Despite the widely held view that surgical treatment is indicated for patients who have neurologic deficits hindering activity of daily life, the new trend is prophylactic surgery when there is radiological evidence of cord compression to avoid further quadriparesis or quadriplegia ${ }^{9}$. Absolute (canal diameter $<10 \mathrm{~mm}$ ) and relative (canal diameter 10-13 mm) have been shown to predispose patients with OPLL in developing more severe deficits earlier in the clinical course. Symptomatic myelopathy typically occurs when the canal diameter is less than $9.4 \mathrm{~mm}(<8 \mathrm{~mm}$ for lower limb weakness) ${ }^{10,11}$. Similarly cervical spinal cord cross sectional area ${ }^{12} \leq 42$ square mm or occupancy ratio ${ }^{13}>40 \%$ to $60 \%$ increases the risk of symptomatic myelopathy. However other dynamic factors like mobility of the cervical spine needs to be considered ${ }^{14}$.

The operative procedure remains controversial .Some study ${ }^{15}$ found no significant difference between the anterior and posterior approaches while others ${ }^{16}$ found the anterior approach to have better postoperative outcome. However, the anterior approach is relatively more difficult and carries potential risk of graft extrusion, CSF (cerebrospinal fluid) leak, excessive venous bleeding, dysphagia and implant failure ${ }^{17}$. High risk patients older than 65 years of age with OPLL but with adequate cervical lordosis may undergo posterior decompressive procedures including laminectomy, laminectomy with posterior fusion or laminoplasty with a modicum of success ${ }^{18}$. Generally, the primary target of the anterior approach is OPLL of the segmental or localized type not extending above $C_{3}$, and the target of the posterior approach, OPLL of the continuous or mixed type ${ }^{4}$. In our study, all the patients underwent posterior decompressive laminectomy as all of them fit criteria for cervical lordosis 5,6 and instability was excluded by dynamic cervical x-rays. All of them were of continuous and mixed types (Table III). In other $\operatorname{study}^{7}$, segmental form is the commonest type. Whether this finding is indicative of ethnic difference or late presentation of the patients to the clinician needs further evaluation.

In this study, the male: female ratio is $11: 2$. Similar $^{19}$ and dissimilar ${ }^{20}$ findings have been quoted by others. Hightest incidence $(30.8 \%)$ is found in the fourth decade(Table II), which is a decade younger than that reported by Naoichi et $\mathrm{al}^{20}$. It may reflect ethnic variation from the Japanese study. In our study, myelopathy with gait disturbance is found in $53.84 \%$ of cases which is in accordance $(\sim 56 \%)$ with literature ${ }^{21}$. Although symptoms are gradual in onset, $10 \%$ patients may precipitously develop myelopathy after mild trauma. Such event was not encountered in our study.

As in other areas of clinical medicine clear delineation of natural history is the basis against which all forms of intervention must be judged. However little is understood about the natural history of OPLL. Contribution of various clinical and radiological parameters remain controversial thus confounding attempt to define a natural history and prognostical surgical outcome There is a distinct paucity of literature in this regard with no prospective study exclusively addressing this problem till date.

Although $73.1 \%$ had improved clinical outcome postoperatively in keeping with the literature $(\sim 72 \%)^{5}$, we have re-affirmed certain traits to be predictive of poor outcome. Age at presentation is an important factor. In this study 2 out of 3 patients who worsened clinically and 3 out of 4 patients who did not improve after surgery were $\geq 60$ year of age corroborating with other studies ${ }^{7,22}$. Symptom duration of less than 6 months to one year is considered critical for good outcome, Hirabayashiet al ${ }^{7}$ reported that myelopathy of more than 2 years duration was associated with poor outcome. In our study, 2 patients each out of those who remained clinically static $(n=4)$ or clinically worsened $(n=3)$ presented with myelopathy for more than 2 years, though statistical significance could not be shown in the results (Table-V). Similarly there is a trend towards poor 
postoperative outcome with pre-operative mJOA score $<11$ despite statistical insignificance $(\mathrm{P}=0.163)$. Hirabayashi at al ${ }^{7}$ considered preoperative JOA score $<7$ to be associated with poor outcome. We have used the modified scoring system. Motor deficit of the lower extremities is significantly increased when the sagittal cervical canal diameter is less than $8 \mathrm{~mm}^{11}$. In this study, 2 patients who worsened clinically in the postoperative period had sagittal cervical canal diameters of $9 \mathrm{~mm}$ and $8 \mathrm{~mm}$, thus predicting poor surgical outcome $(\mathrm{P}=0.034)$. Cross sectional area ${ }^{12}$ of the cervical spinal cord at the level of maximum compression less than 42 square $\mathrm{mm}$ is also associated with greater severity of myelopathy postoperatively. In our study, 2 patients from the poor outcome group (status quo and worsened) had cross-sectional area of cord 40.8 square $\mathrm{mm}$ and 42 square $\mathrm{mm}$. MRI cord signal changes preoperatively were also predictive of poor outcome $(\mathrm{P}=0.041)$. Most of the patients who had pre-operative bladder dysfunction had poor postoperative outcome $(\mathrm{P}<$ 0.001). The impact of co-morbid conditions could not be ascertained as few patients had comorbid conditions, a finding which had been noted earlier ${ }^{21 .}$.

\section{Conclusion}

Our study has attempted to look into putative prognostic factors determining the surgical outcome in symptomatic cervical OPLL patients. We have found that pre-operative functional status of the patient in terms of modified Japanese Orthopedic association scoring, bladder symptoms. MRI cord signal changes and lower cross-sectional area of spinal cord at the level of maximum compression to be predictive of poor postoperative outcome.

\section{References}

[1]. Key CA. Paraplegia depending on disease of the spine Guys Hosp Res. 1838;3:17-34

[2]. Tsukimoto H. An autopsied case of compressive myelopathy with a callous formation in the cervical spinal canal. Arch JpnChir 1960; 29:1003-7.

[3]. Bakay L. Ossification of the posterior longitudinal ligament. In Wilkins RH, Rengachari SS ( ${ }^{\text {st }}$ edn) Neurosurgery, New York:McGraw Hill, 1985; 2243-4.

[4]. Henary H. Schmidek and David W. Robert. Schmidek and Sweet Operative Neurosurgical Techniques; $5^{\text {th }}$ Edn., Vol.2, Philadelphia: Saunders Elsevier, 2006; 1879-93.

[5]. Benzel EC, Lancon J, Kesteron L, Hadden T. Cervical laminectomy and dentate ligament section for cervical spondylotic myelopathy. J. Spinal Discord 1991; 4:226-95.

[6]. Chiba K, Toyama Y, Watanabe M, Marviwa H, Matsunoto M, Hirabayashi K. Impact of longitudinal distance of the cervical spine on the results of expansive open door laminoplasty. Spine 2000; 25(22):2893-8.

[7]. Hirabayashi K, Watanabe K, Wahano K, Suzuki N, satomi K, Ishii Y. Expansive open door laminoplasty for cervical spine stenotic myelopathy. Spine 1983; 8(7): 693-9.

[8]. Sauders RL, Pikus HJ, Ball P. Four level cervical corpectomy. Spine 1998; 23: 2455-61.

[9]. Epstein N. The surgical management of ossification of the posterior longitudinal ligament in 51 patients. J. Spine Discord 1993; 6(5): 432-55

[10]. Epstein N. Cervical ossification of the posterior longitudinal ligament. In: Wilkins RH and RengachariSS(eds): Neurosurgery $2^{\text {nd }}$ Edn. New York; McGraw Hill 1996; 3786-7.

[11]. Koyanagi I, Imamura H, Fusimoto S, Hida K, Iwasaki Y, Hondin K. Spinal canal size in ossification of the posterior longitudinal ligament of the cervical spine. SurgNeuro 2004; 62: 286-91.

[12]. Okada Y. Ikata T, Yamada H, Sakamoto R and Katosh S. Magnetic resonance imaging studies on the result of surgery for cervical compressive myelopathy. Spine 1993; 18(14): 2024-9.

[13]. Matsunaga S, Sakou T, Taketomi E, Yamaguchi M and Okano T. The natural course of myelopathy caused by ossification of the posterior longitudinal ligament in cervical spine. ClinOrthopRelat Res 1994; 305:168-77.

[14]. While AA and Punjabi MM, Clinical biomechanics of the spine. $2^{\text {nd }}$ Edn, Philadelphia : JB. Lippincott 1990 ; PP 722.

[15]. Jain SK, SalunkePSmVyA KH, Behari SS, Banerji D, Jain VK. Multisegmental cervical ossification of the posterior longitudinal ligament: Anterior vs posteriorapproach. Neurology India 2005; 53:283-5.

[16]. Kawano H, Honda Y, Ishii H, Sato K, Oku T, Kubota T. Surgical treatment for ossification of posterior longitudinal ligament of the cervical spine. J Spinal Discord 1995; 8(2): 145-50.

[17]. Emery SE, Bohlman HH, Bolesta MJ, Jones PK. Anterior cervical decompression and arthrodesis for the treatment of cervical spondylotic myelopathy - two to seven years follow up. J Bone Joint Surg Am 1998; 80(7): 941-51.

[18]. Kato Y, Iwasaki M, Fuji T, Yonenobu K, Ochi T.Long term followup results of laminectomy for cervical myelopathy caused by ossification of the posterior longitudinal ligament. J Neurosurg 1998; 89(2): 217-23.

[19]. Itoh T, Tsuji H. Technical improvement and results of laminoplasty for compressive myelopathy in cervical spine. Spine 1985; 10:729-36

[20]. Naochi T. Ossification of the posterior longitudinal ligament of the spine. J Japanese Ortho Asso 1981; 55: 71-84.

[21]. Ono K, Ota H, Tada K, Hamada H, Takaoka K,Ossified posterior longitudinal ligament: a clinicopathological study. Spine 1977; 2:126-38.

[22]. Ogawa Y, Toyama Y, Chiba K, Matsumoto M, Nakamura M, Takaishi H, et al. Long term results of expansile open door laminoplasty for ossification of the posterior longitudinal ligament of the cervical spine. JNeurosurg (Spine) 2004; 1(2): 168-74 